\title{
Avyaya Analyzer: Analysis of Indeclinables using Finite State Transducers
}

\author{
N. Murali \\ Department of Computer Applications \\ S.V. Vedic University \\ Tirupati
}

\author{
Prof. R.J. Ramasree \\ Department of Computer \\ Science \\ R.S. Vidyapeetha, \\ Tirupati
}

\author{
Prof. K.V.R.K. Acharyulu \\ Department of Vyakarana \\ R.S. Vidypeetha, \\ Tirupati
}

\begin{abstract}
In Sanskrit, avyaya i.e., the indeclinable, plays an important role in the construction of a sentence and can be used as preposition, interjection, particle, conjunction or an adverb. To understand a given sentence, a thorough cognizance of the avyaya is necessary. This paper briefly describes the avyayas, types of avyayas and role of avyayas. An avyaya analysis tool (avyaya Morphological Analyzer) has been described here in using FST. The system described in this paper reads the input and produces the derivational morphological information. This paper portrays a simple and straight forward technique to analyze the avyayas.
\end{abstract}

\section{General Terms}

Natural Language Processing (NLP) - Morphological Analyzer

\section{Keywords}

Avyayas - Kr $\square$ danta - Nipāta - Conditional avyayas Relational avyayas $-k r \square t$-taddhita

\section{INTRODUCTION}

Natural Language Processing (NLP) is a branch of Artificial Intelligence and deals with the Analysis of Human Languages. Each language consists of a set of words called lexicon and a set of rules called grammar. These enable the use of words to form cognitional valid sentences. NLP deals with both the Spoken as well as Written Languages. The goal of a researcher in NLP is to develop a Parser to analyze any human language. A typical language parser can be divided into 3 components [8] viz., Morphological Analyzer, Local Word Grouper and Core Parser. A Sentence is the input for the Parser. A sentence is a group of interrelated words. Every word in the sentence has its own meaning and is encoded grammatically. Further it is related to other words in the sentence. Morphological Analyzer (MA) will take each word in the sentence and retrieve the information encoded in the word. With the help of the information produced by the MA, Local Word Grouper (LWG) will try to identify the phrases in the sentence by grouping the words which have mutual relationship in the sentence. Parser will generate the parsed structure of the sentence.

\subsection{Avyayas}

Sanskrit is the oldest, morphologically rich and most complex language in the world. Pān $\square$ inī grammar is the most widely accepted grammar of Sanskrit. In Sanskrit, the words can be broadly classified into 2 categories viz. Declinable and Indeclinable [1]. Figure 1 illustrates this.

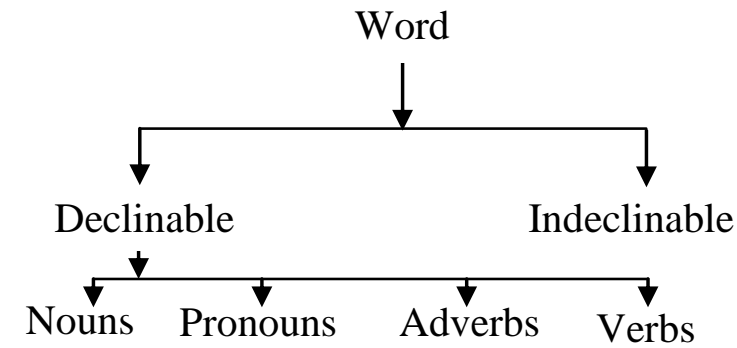

Figure 1: Classification of Words

Declinable or inflectional words are those words whose base form can be changed or inflected. For example, the base form prātipadikam or lemma Rāma can be inflected in 7 vibhaktis i.e., cases and numbers. These declinable/inflectional words can again be categorized as Nouns, Pronous, Adverbs and Verbs. In Sanskrit, indeclinable words are called avyayas. A Sanskrit grammarian has given a beautiful and simple definition for avyayas

$$
\begin{aligned}
& \text { सहशं त्रिषु लिङ्गेषु सर्वासु च विभक्तिषु । } \\
& \text { वचनेषु च सर्वेषु यन्न व्येति तदव्ययम् ।। } \\
& \text { Sadr } \square \text { śam } \square \text { tris } \square \text { u lin } \square \text { gēs } \square \text { u sarvāsu ca vibhaktis } \square u \text { / } \\
& \text { Vacanēs } \square \text { u ca sarvese } \square \text { u yanna vyêti tadavyayam // }
\end{aligned}
$$

The meaning of the sloka states that the words that cannot be changed or inflected or which remain immutable in all genders, numbers and cases; are called avyayas [1][2][6][7][10]. But, there is an exception to some nouns (Nominative or Locative), which have only one declension e.g. $\bar{a} d a u, s a m \square v a t, s v a r, s v a \bar{h} \bar{a}, s v a d h \bar{a}$ etc. Figure 2 in the next page illustrates various types of avyayas. Some grammarians have classified avyayas into Substantive and Non-substantive [6] [7]. The examples for Substantive avyayas are asti, adau, sam $\square$ vat, svar etc. Non-substantive avyayas can be further divided into two types i.e., Conditional and Relational. cêt, yat-tat, yathā-tathā, yadìtarhi, yatra-tatra, yāvat-tāvat etc. are the examples of Conditional avyayas, while atha, api, iti, iva, èva, èvam, kila, khalu, ca, tu, manye, vat, vā etc. for relational avyayas 


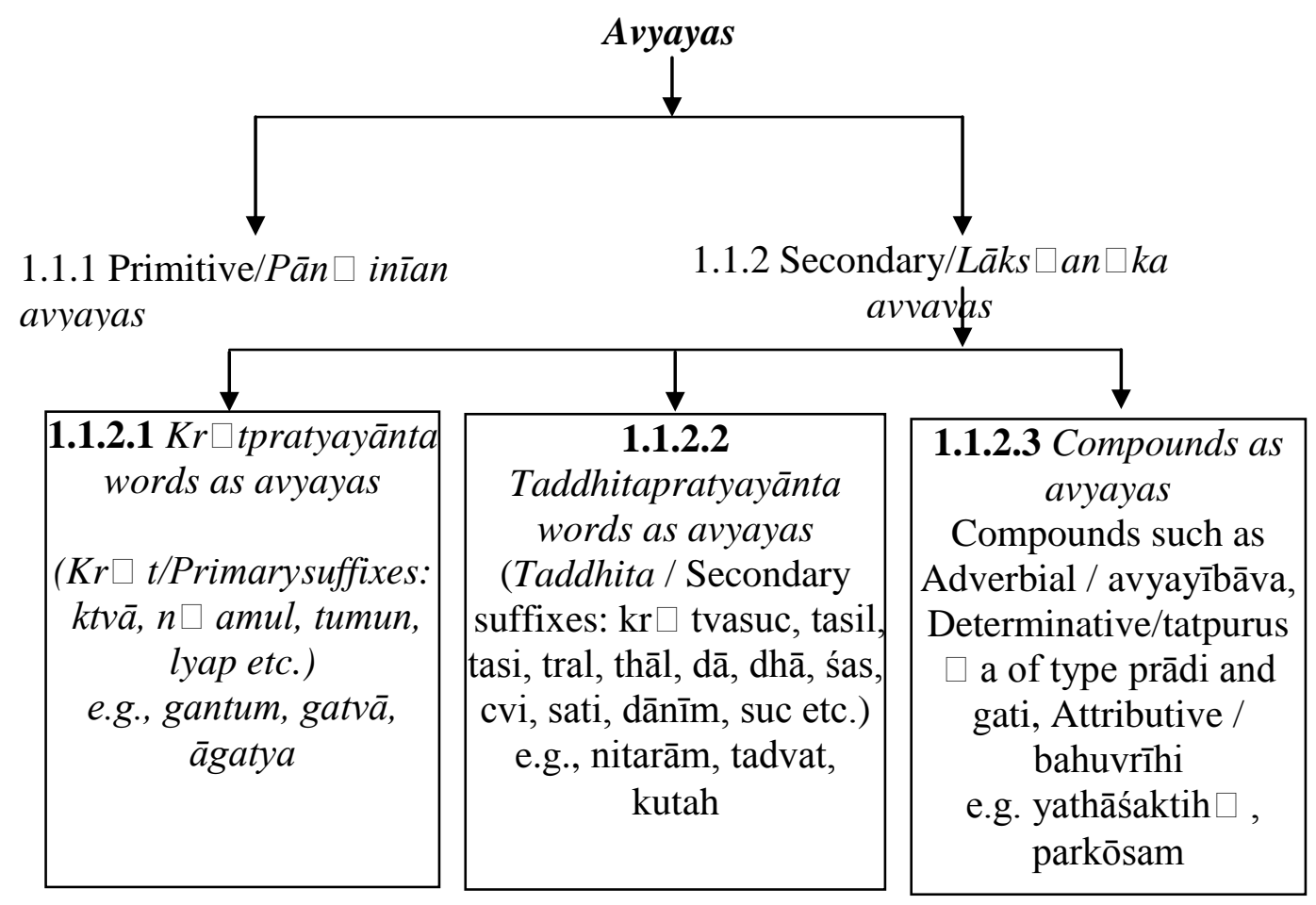

Figure 2: Classification of avyayas

Avyayas can be classified into two types i.e., Primitive/ Pān $\square$ iñ̄an avyayas and Secondary / Lāks $\square a n \square k a$ avyayas.

\subsubsection{Primitive/Pān $\square$ inīan avyayas}

These types of avyayas are directly named by the Sanskrit grammarian $P \bar{a} n \square i n \bar{\imath}$ as nipātas. These avyayas can be used as prepositions, interjections, particles and conjunctions and can be called as nipātas i.e., exceptional or irregular forms [6]. All nipātas are indeclinable [7]. All upasargas/prefixes can also be treated as nipātas and are indeclinable.

\subsubsection{Secondary / Lāks $\square a n \square k a-s$ avyayas}

These are used as adverbs or adjectives. Kr $\square$ dantāvyayas, taddhitāntāvyayas and adverbial, determinative (of type prādi, gati) and attributive types of compounds fall into this category.

\subsubsection{Kr $\square$ tpratyayāntawords as avyayas}

$K r \square$ tpratyaya / Primary suffixes are used to form nouns (Nominalization) and avyayas from roots [1][2][6][10][11]. These avyayas denote some action, which have a relation to the main verb in the sentence.

\subsubsection{Taddhitapratyayānta words as avyayas} Ttaddhitapratyaya / Secondary suffixes are those suffixes that are used to form nouns or avyayas from other nouns [1][2][6][10].

\subsubsection{Compounds as avyayas}

Some compounds such as Adverbial / avyaȳ̄bhāva, Determinative / tattpurus $\square a$ (of type prādi and gati), Attributive / bahuvrīhi also act as avyayas.

\section{FINITE STATE TRANSDUCER (FST)}

FST is an extension of Finite State Automata and can generate output symbols [9]. Morphological Analyzers/Generators can be developed using FST. The transducer is defined as [9]

$$
\mathrm{T}=\left(\mathrm{Q}, \Sigma, \mathrm{q}_{0}, \mathrm{~F}, \delta\right)
$$

$\mathrm{Q}$ is a finite set of $\mathrm{N}$ states $\mathrm{q} 0, \mathrm{q} 1, \mathrm{q} 2 \ldots . . \mathrm{qN} . \Sigma$ is a finite set of alphabet of complex symbols. Each complex symbol is composed of an input - output pair i : o; one symbol $i$ from an input alphabet $I$, and one symbol $o$ from output alphabet $O$, thus $\Sigma \subseteq I \mathrm{X} O, I$ and $O$ may each also include the epsilon symbol " $\varepsilon$ " i.e. empty symbol or transition label. State transition labels are of 4 kinds [11] $(\sigma: \gamma)$, indicates that $\sigma$ read from the surface form and $\gamma$ is written; $(\sigma: \varepsilon)$ indicates that $\sigma$ is read from the surface form and $\varepsilon$ i.e., nothing is written; $(\varepsilon: \gamma)$ indicates that nothing is read but $\gamma$ is written; $(\varepsilon: \varepsilon)$ indicates that a state transition occurs without reading or writing. $\mathrm{q}_{0}$ is the initial state. $\mathrm{F}$ is a set of final states, $\mathrm{F} \subseteq$ Q. $\delta(\mathrm{q}, \mathrm{i}: \mathrm{o})$ is the transition function between states. Given a state $\mathrm{q} \in \mathrm{Q}$ and complex symbol $\mathrm{i}: \mathrm{o} \in \Sigma, \delta(\mathrm{q}, \mathrm{i}: \mathrm{o})$ returns a new state $\mathrm{q}^{\prime} \in \mathrm{Q} . \quad \delta$ is thus a relation from $\mathrm{Q} X \Sigma$ to $\mathrm{Q}$.

\section{AVYAYA ANALYZER}

Avyaya Analyzer (AA) was designed based on FST. FST can be built to accept letters, strings or patterns. A string or pattern is a group of characters. Because of the complex and agglutinative nature of most of the Indian languages, transducers based on strings and patterns are preferred. In this tool, unlike letter transducers, transitions on strings take place. Strings generally are valid upapadas, prefixes, roots, suffixes and feature sequences in the language.

Avyaya Analyzer deals fully with the primitive type avyayas i.e., 1, and $K r \square$ dantas / Primary suffixes i.e., 1.1.2.1 and partly with Taddhitas / Secondary suffixes i.e., 1.1.2.2. Dealing with avyayas of type 1 is very simple because it has already been defined as avyayas by $\boldsymbol{P} \bar{a} \boldsymbol{n} \square$ iñ̄in nipātas. A list of avyayas was collected from the text "avyaya kōsa", which contains 900 avyayas written by Srivatsankacharya. Here a simple lookup is enough to identify the avyayas. Some of the examples of type 1 avyayas are asti, ädau, atha, 
api, iti, iva, èva, èvam, katham, kila, khalu, ca, tu, manyē, $v a t, v \bar{a}$ etc., avyayas of type 1.1.2.2 had been encoded with information and play a vital role in understanding the sentence. Consider the following examples

$$
\begin{aligned}
& \text { Gantum means "to go" } \\
& \bar{A} \text { gantum means "to come" } \\
& \text { Gatvā means "having gone" } \\
& \text { Agatya means "having come" }
\end{aligned}
$$

All the above examples were derived from the single root gam, prefix $\bar{a}$ and $k r \square t$ suffixes tumun, ktvā and lyap. Each word indicates a different meaning because of the suffixes. All these avyayas indicate incomplete action of their constituent verbal roots and have a relation to the main verb in the sentence and act as an adverb. Let us see the avyayas in action in a sentence

Sentence: aham $\square$ gantum icCāmi.

POS: Sub avyaya verb

Meaning: I wish to go.

Sentence: aham $\square$ ägantum icCāmi.

POS: sub avyaya verb

Meaning: I wish to come.

Sentence: bhavān tatra gatvā vadatu.

POS: sub avyaya avyaya verb

Meaning: having gone there, you tell

Sentence: atra a agatya upaviśatu.

POS: avyaya avyaya verb

Meaning: having come, sit here.

In all the examples given above, avyayas act as adverbs. Both the avyaya and main verb are mutually dependent on each other and it is impossible to understand the meaning of the sentence without gaining a proper understanding of the avyaya.

\subsection{Previous work}

Dr. Girish Nath Jha, Special centre of Sanskrit Computational Linguistics, Jawaharlal Nehru University, New Delhi ${ }^{1}$ has dealt with the avyayas to some extent. The sample output obtained from the website is presented below in roman transliteration form

Abhijñātum [Abhi jñā, 9, tumun, 0, avy]_KR

Abhijñātum [Abhi jñā, 9, tumun, 0, avy]_KR

Abhiūhitum [Abhi ūūha, 1, tumun, 0, avy]_KR

Abhiūhitum [Abhi ūūha, 1, tumun, 0, avy] KR

An $\square$ gìkr $\square$ tya [_not found]

$\mathrm{Akr} \square \mathrm{vā}[1.1]$

$\bar{A}$ krāntum [_1.1/2.1]

Apa sārya [_not found]

pra tyāgatya [_not found]

Laks $\square \mathrm{ikr} \square$ tya [_not found]

When the test data of 122 avyayas was given to this online tool, 77 avyayas were found unidentified and 13 avyayas were not recognized correctly. The precision is $74.50 \%$ and recall is $53.52 \%$. Dr. Gerard Huet, Inria, France ${ }^{2}$ is also working on $k r \square$ dantas Dr. P. Amba Kulkarni, Department

\footnotetext{
${ }^{1} \mathrm{http} / / /$ sanskrit.jnu.ac.in/kridanta/ktag.jsp

${ }^{2}$ http://sanskrit.inria.fr/DICO/reader.html
}

of Sanskrit Studies, University of Hyderabad ${ }^{3}$ and IIITH $^{4}$, Hyderabad are also working on Morphological Analyzer for Sanskrit.

\subsection{Design}

The structure of avyaya may be

$$
\text { [[Upapada }][\text { Upasarga]root + suffix }]
$$

Upapada and upasarga/prefix are optional. The avyaya Analyzer will give the derivational morphological information of an avyaya i.e., the upapada, upasarga, root and suffix information.

\subsubsection{Representation of linguistic information}

This system relates the root and linguistic features to the surface form through a set of transformations. 2000 verbal roots, $120 \mathrm{kr} \square t$ suffixes (out of which four suffixes are related to avyayas), 26 upasargas/prefixes and nearly 500 upapadas were collected. With the combination of all these upapadas, prefixes, roots and suffixes, we can generate a large number of avyayas which are not productive [9]. The upapada, upasarga, root and suffixes acquire different forms due to euphonic transformations between them. Hence, each and every possible phonetic change of roots, suffixes, upasargas, and upapadas were written manually ${ }^{5}$ along with the necessary linguistic features. Morphological dictionaries for upapadas, upasargas, roots and suffixes were created. An example of the possible phonetic changes in upapada, upasarga, root and suffix are given below. The second field indicates the lemma and the first field indicates all possible phonetic changes of the second field in context of euphonic change. For computational purpose, the data is presented in WX transliteration scheme. There are several converters available to convert the text from Roman to Unicode and vice-versa.

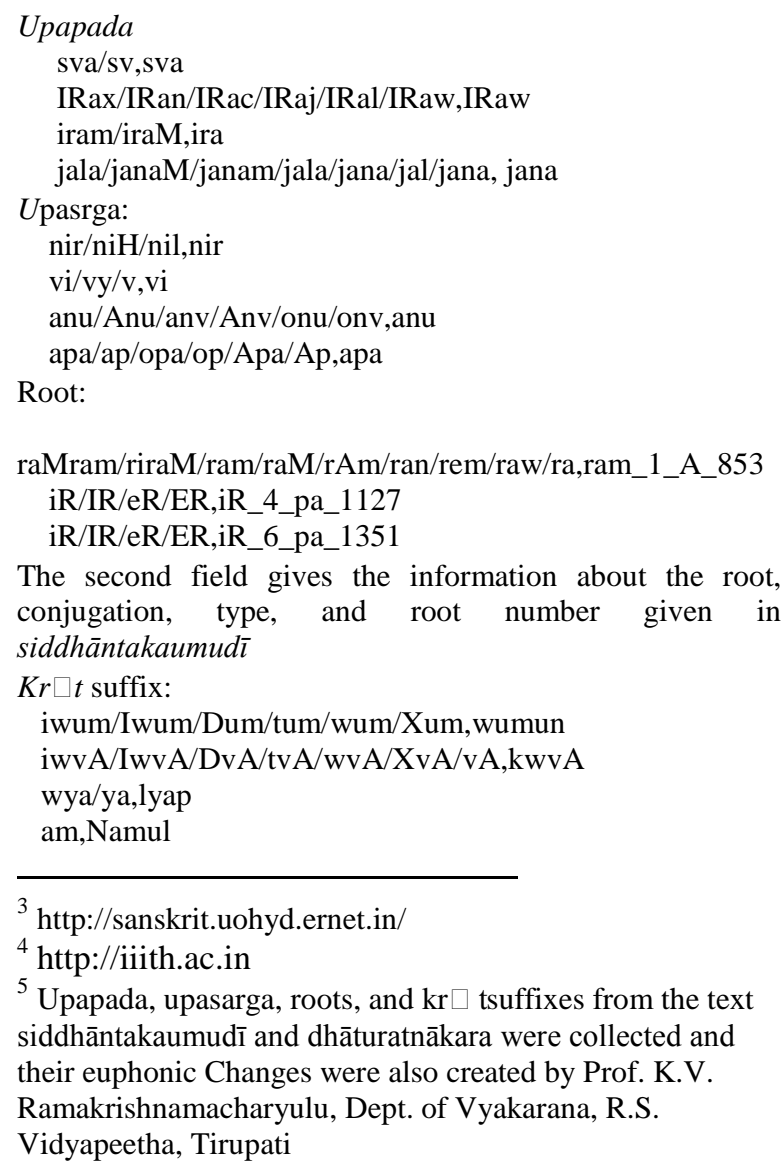

The second field gives the information about the root, conjugation, type, and root number given in siddhāntakaumudī

$K r \square t$ suffix:

iwum/Iwum/Dum/tum/wum/Xum,wumun iwvA/IwvA/DvA/tvA/wvA/XvA/vA,kwvA wya/ya,lyap am,Namul

\footnotetext{
${ }^{3}$ http://sanskrit.uohyd.ernet.in/

${ }^{4}$ http://iiith.ac.in

${ }^{5}$ Upapada, upasarga, roots, and $\mathrm{kr} \square$ tsuffixes from the text siddhāntakaumudī and dhāturatnākara were collected and their euphonic Changes were also created by Prof. K.V. Ramakrishnamacharyulu, Dept. of Vyakarana, R.S. Vidyapeetha, Tirupati
} 


\subsubsection{Identification of avyayas}

It can be checked whether the word is avyaya or not by noticing whether the word is nipatta or by comprehending its suffix. If the word is nipāta, then treat it as avyaya and stop. If the word ends with the suffix related to avyaya, then it return suffix info and strips the suffix and checks for upapada. As upapada and upasarga are optional, they may or may not be present in the given word. Hence, if upapada is present, then return the upapada info and strip it, or else return nothing and remove nothing. Then the presence of upasarga may be checked for. If upasarga is found, then return upasarga info and strip it or else return nothing and remove nothing. Then check whether the remaining part of the word is the root or not. If it is, then return the root info or return nothing and stop. The sample output of the avyaya Analyzer is given below. Figure 3 in the next page illustrates the process of analyzing the avyaya using Finite State Transducers.

The sample output is presented here in WX transliteration scheme:

$<$ Word: aBijFAwum $><$ vargaH: avyaya $><$ lifgam: $\mathrm{xxx}><$ ViBakwi: $\mathrm{xxx}\rangle<$ vacanam: $\mathrm{xxx}><$ level: 1><upapaxam: $\mathrm{xxx}><$ upasargaH: $\mathrm{aBi}><$ prAwipaxikam: aBijFAwum/jFAwum $><$ XAwuH: jFA $><$ prawyaya: wumun\#><gaNaH: $9>\langle$ paxI: pa $>$

$<$ Word: afgIkqwya $><$ vargaH: avyaya $><$ lifgam: $\mathrm{xxx}><$ ViBakwi: $\mathrm{xxx}><$ vacanam: $\mathrm{xxx}><$ level: 1 $><$ upapaxam: afgI $><$ upasargaH: $\mathrm{xxx}>\langle$ prAwipaxikam: afgIkqwya/kqwya $><$ XAwuH: kq\#kqw $><$ prawyaya: lyap\#><gaNaH: 8\#5\#6\#7><paxI: u\#pa>

$<$ Word: akqwvA $><$ vargaH: avyaya $><$ lifgam: $\mathrm{xxx}><$ ViBakwi: $\mathrm{xxx}><$ vacanam: $\mathrm{xxx}><$ level: 1><upapaxam: $\mathrm{xxx}><$ upasargaH: naF_naFwawpuruRaH $><$ prAwipaxikam: akqwvA/kqwvA $>\langle$ XAwuH: kq\#kqw $><$ prawyaya: kwvA\#><gaNaH: 8\#5\#6\#7><paxI: u\#pa>

$<$ Word: AkrAnwum $><$ vargaH: avyaya $>\langle$ lifgam: $x x x>$ $<$ ViBakwi: $\mathrm{xxx}\rangle\langle$ vacanam: $\mathrm{xxx}\rangle\langle$ level: 1><upapaxam: $\mathrm{xxx}>$ <upasargaH: Af $>\langle$ prAwipaxikam: AkrAnwum/krAnwum $><$ XAwuH: kram $><$ prawyaya: wumun\#><gaNaH: 1><paxI: pa>
$<$ Word: apasArya $><$ vargaH: avyaya $><$ lifgam: $\mathrm{xxx}\rangle\langle$ ViBakwi: $\mathrm{xxx}\rangle\langle$ vacanam: $\mathrm{xxx}\rangle<$ level: 1 $><$ upapaxam: $\mathrm{xxx}><$ upasargaH: apa $><$ prAwipaxikam: apasArya/sArya $><\mathrm{XAwuH}$ : sA\#san\#sAr\#sq $><$ prawyaya: lyap\#><gaNaH: 1\#4\#8\#10\#3><paxI: pa\#u>

$<$ Word: prawyAgawya $><$ vargaH: avyaya $><$ lifgam: $\mathrm{xxx}><$ ViBakwi: $\mathrm{xxx}><$ vacanam: $\mathrm{xxx}><$ level: 1><upapaxam: $\mathrm{xxx}><$ upasargaH: prawi,Af $\rangle\langle$ prAwipaxikam: prawyAgawya/gawya $><$ XAwuH: gam $><$ prawyaya: lyap\#><gaNaH: 1><paxI: pa>

$<$ Word: lakRylkqwya $><$ vargaH: avyaya $><$ lifgam: $x x x>$ $<$ ViBakwi: $\mathrm{xxx}><$ vacanam: $\mathrm{xxx}><$ level: 1$\rangle<$ upapaxam: lakRya $><$ upasargaH: $\mathrm{xxx}><$ prAwipaxikam: lakRylkqwya/kqwya $><\mathrm{XAwuH}$ : kq\#kqw $><$ prawyaya: lyap\#><gaNaH: 8\#5\#6\#7><paxI: u\#pa>

\section{Evaluation}

A test data consisting of 28,000 words was prepared by collecting various children stories from candamama monthly magazine published during a year. Out of which 122 avyayas formed by the primary suffixes (1.2.2.1) have been collected and tested. The tool was evaluated directly based on the Morphological analysis of a given avyaya. The system was evaluated by calculating precision and recall for avyayas.

$$
\begin{aligned}
& C=\text { Number of Correct analysis, } \\
& M=\text { Number of Missed analysis } \\
& W=\text { Number of Wrong analysis } \\
& \text { Precision }=C /(C+W) \\
& \text { Recall }=C /(C+M)
\end{aligned}
$$

The avyayas were analyzed with a precision of $96.72 \%$ and with a recall of $98.36 \%$

\section{LIMITATIONS}

This tool can identify up to one upapada, two upasargas in a sequence from the word. As there is no limit on number of upapadas and upasargas that should be present in the word, the present system will fail to recognize the word when it contains more than one upapada, and two upasargas.

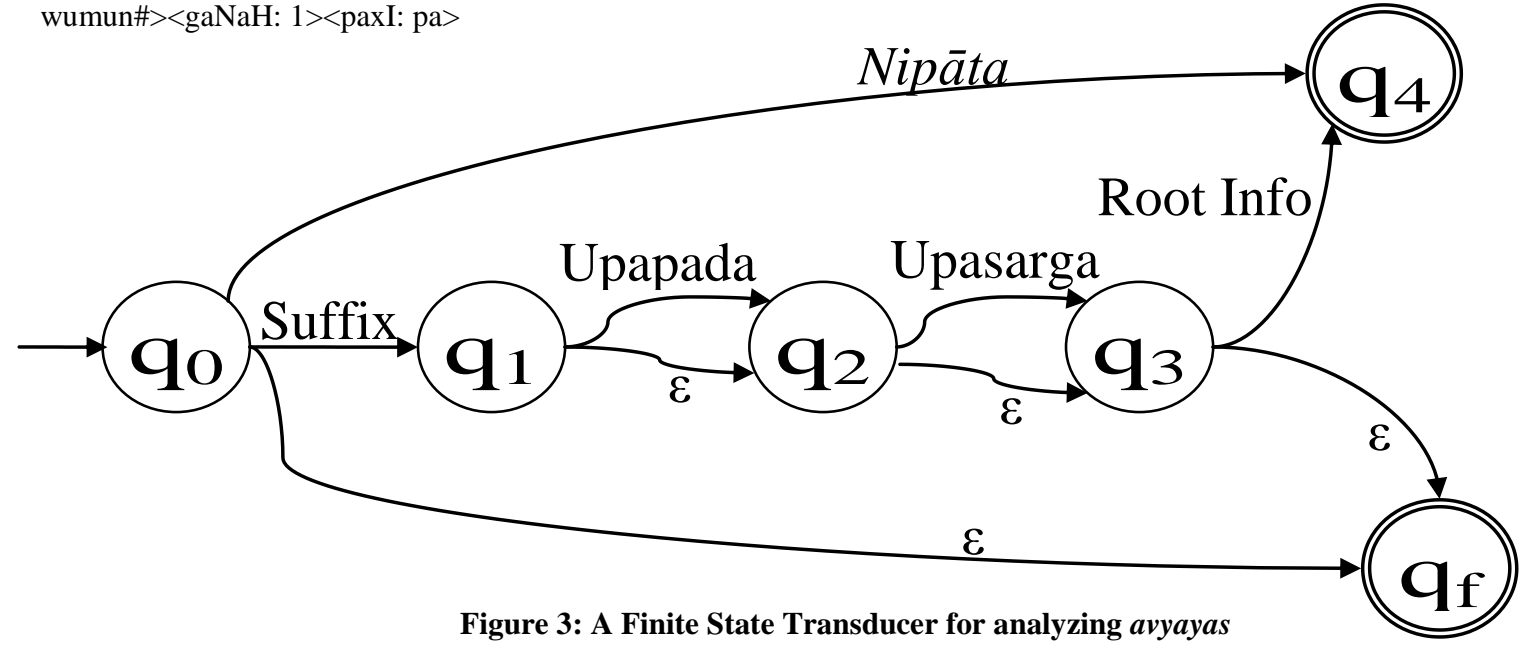

This tool cannot handle when two or more primitive avyayas (1.1.1) are presented in sandhi form (euphonic transformation). Only a few secondary suffixes (1.1.2.2) like vaw, atasuc, etc have been covered here. As it is told earlier, compounds which act as avyayas (1.1.2.3.) have not been taken up in the present study. $K r \square t$ suffixes related to Vedas have also not been covered in the present study. 


\section{CONCLUSION}

This paper presents a practical and more sophisticated approach to analyze avyayas. As the morphological data and the program modules are independent of each other, it is easy to add new data or change the data without changing the modules. This tool was developed using PERL and it can be easily integrated with any Morphological Analyzers for Sanskrit. The morphological dictionary for roots, $\boldsymbol{k} \boldsymbol{r} \square \boldsymbol{t}$ suffixes (except those which are related to vaidikaprakaran $\square a$ ) and prefixes are complete, but upapada dictionary contains limited terms. The right to left approach was also developed to deal with those upapadas which are not available in morphological dictionary which is still under testing.

\section{ACKNOWLEDGEMENT}

Authors thank Dr. Viroopaksha V. Jaddipal, Associate Professor, R.S. Vidyapeetha, Dr. Manoj Kumar Mishra, Assistant Professor, S.V. Vedic University, Mr. Sriramachandra Sarma, Assistant Professor, S.V. Vedic University, Sri Vinayak Bhat, Assistant Professor, S.V. Vedic University, Dr. K. Ushasharma, Asst. Professor, S.V. Vedic University for giving valuable suggestions and Mr. Veluvarti Srinvasa Narayana, Acharya Student, R.S. Vidyapeetha for supplying linguistic information.

\section{REFERENCE}

[1] Chakradhar Nautiyaalhansa Shastri, 1966 "br $\square$ had anuvāda-candrikā ", Motilal Banarsidas, New Delh

[2] Dr. R.V.R. Krishna Sastri, 1997 "sam $\square s k r \square$ to vyākaran $\square$ am’, Krishnanada Mutt, Hyderabad

[3] Sri Srvatsankacharya, 1971 "avyaya kōśa (A Dictionary of Indeclinables", The Sanskrit Education Society, Chennai

[4] Bhat $\square \mathrm{t} \square$ ōji Diksitạ “siddhāntakaumudī”, 1983 Motilal Banarsidas, New Delhi
[5] Muni lāvan $\square$ ya vijayasūri, "dhāturatnākara", I-VII Volumes Motilal Banarsidas, New Delhi

[6] M. Monier-Williams, "Sanskrit-English Dictionary", online dictionary www.sanskritlexicon.uni-koeln.de/ monier /indexcaller.php

[7] Declension - Indeclinables available at : www.sanskritsanscrito.com.ar/en/sanskrit_sanskrit6/ind eclinables.shtml

[8] Akshar Bharati, Vineet Chaitanya, Rajeev Sanghal, "Natural Language Processing - A Paninian Perspective", Prentice Hall of India, New Delhi.

[9] Daniel Jurasky \& James H. Martin, Third Reprint, 2004 "Speech and Language Processing", Pearson Education

[10] Girish Nath Jha, Muktanand Agrawal, Subash, Sudhir K. Mishra, Diwakar Mani, Diwakar Mishra, Manji Bhadra, Surjit K. Singh "Inflectional Morphology Analyzer for Sanskrit", First International Sanskrit Computational Linguistics Symposium, Paris, October 29-31, 2007

[11] Bhuvaneshwari C Melinamath, Shubhangi D.C., A G Mallikarjunmath, "Robust Morphological analyzer to Capture Kannada noun Morphology”, 2011 International Conference on Future Information Technology, IPCSIT vol.13 (2011) IACSIT Press, Singapore

[12] Alberto Sanchis, David Pic'o, Joan Miquel del Val, Ferran Fabregat,Jes 'us Tom'as, Mois'es Pastor, Francisco Casacuberta, Enrique Vidal "A Morphological Analyser for Machine Translation Bsed on Finite-stateTransducers"

[13] Akshar Bharati, Amba Kulkarni, V Sheeba, "Building a Wide Coverage Sanskrit Morphological Analyzer: A Practical Approach", IIT Bombay 